\title{
Preface: Changing the world, one idea at a time
}

Change is indeed the essence of life in the early twenty-first century, but even so, sometimes - when I pause to consider the breadth of the changes I've witnessed during my life-I am truly astonished. When I was a child in New York City (in the dim-and-distant 1950s), we often rode on trolley cars (what Europeans call trams); and they were found not only in large cities, but in every sizeable town, including the one in which I live now (Edmond, Oklahoma). Today, of course, trolleys exist only in memory, in museums, and in a small number of U.S. cities. Television was brand new, screens were tiny, showed only black and white images, and — even worsethere was almost nothing to watch! Frozen food was a new fad, and from it, I soon learned lasting lessons about the misleading nature of advertising; in my ten-year-old mind, the foods inside should, I thought, resemble pictures shown on the front of the packages. Of course they did not, and this gave me an early taste of media-based disillusionment! Few people I knew had ever flown on an airplane, and fewer still had ever visited Europe or even Mexico. Having a college degree was a relative rarity, and I knew very few women who worked full time outside their homes. Air conditioning was a luxury few could afford, and was to be found mainly in movie theaters and restaurants. As for technology, small communication devices existed only in comic books or science fiction stories, computers were huge devices used only by a few people who understood their deep mysteries; music came on black, breakable (and later, unbreakable) discs, tape recorders had actual reels that often got tangled, and no one had ever heard the term "download". The only way to capture moving images of other people was by means of $8 \mathrm{~mm}$ cameras, and the idea of shopping electronically would have seemed totally incomprehensible. And medical procedureseven relatively basic ones such as removal of an appendix-required long stays in the hospital (eight days, when my own appendix was removed in 1951); now, due to new surgical techniques, a one-day stay will often suffice - as was true, in recent years, for both my daughter Jessica and wife Rebecca! So, yes, the world - and more importantly, everyday life - has changed tremendously during my lifetime.

Why have all these transformations occurred in just a few decades? Obviously, many factors are involved, ranging from rapid progress in 
science and engineering, which provided the foundation for many advances, through rising standards of living and education, as well as the huge sums spent by large corporations and the military on research and development. But overall, I believe - passionately! - that a key driver of all this change has been the ideas created by individuals who then, through a long and complex process, converted them into real products, services, or means of production. In short, I believe that it is these individuals - the individual entrepreneurs - who, through their collective creativity and efforts, have given us the world in which we now live.

Of course, having an idea is one thing; developing it into something tangible is quite another. The process involved is long and complex, and to accomplish it, entrepreneurs need many skills and personal resourcestools that are helpful, if not truly essential, for making the possible real. Identifying these as clearly as current evidence permits is the key goal of this book; offering suggestions that can help entrepreneurs to develop them, is another. Each chapter, then, examines distinct tools useful to entrepreneurs in their journey from ideas to reality, and together, the information included offers as broad and comprehensive an overview as I could produce, of what these tools are and why they are important. Many entrepreneurs fail, and it is a central thesis of this volume that in many instances, they do so because they are lacking in some of the essential tools or resources.

This logic has led me, on many occasions, to ponder yet another question: "How many potentially valuable ideas 'die on the vine' — are generated by individuals (potential entrepreneurs), but are then never developed?" My musings suggest to me that this may be a much larger number than most of us would prefer to imagine. And these thoughts also lead me to ask, "How many such ideas are fading away, unknown, even today?" If this book, and the contents it presents, can help assure that even a few of these ideas do actually see the light of day (because the people who generate them have gained a better understanding of what they need to achieve this transformation), then it will have accomplished its major purpose.

In any case, get ready for an intriguing journey-one that will take us from the cognitive origins of ideas, through examination of the many factors that influence their development, and the likelihood that they will ever become more than ephemeral images of something new and better flickering through the minds of specific persons. It is far better, I believe, for these ideas to actually move from the realm of the possible into reality. Why? Because such transformations benefit not only the persons who create the ideas, but the rest of us too, by changing the world in ways we cannot now predict or, perhaps, even imagine. So, please permit me to close with a warm salute to entrepreneurs - who are, in a very real sense, the true engines of change and improvement in human life. 